\title{
Human adipose-derived stem cell transplantation as a potential therapy for collagen Vl-related congenital muscular dystrophy
}

\author{
Vitali Alexeev ${ }^{1}$, Machiko Arita ${ }^{1}$, Adele Donahue ${ }^{1}$, Paolo Bonaldo², Mon-Li Chu and Olga Igoucheva ${ }^{1 *}$
}

\begin{abstract}
Introduction: Congenital muscular dystrophies (CMD) are a clinically and genetically heterogeneous group of neuromuscular disorders characterized by muscle weakness within the first two years of life. Collagen Vl-related muscle disorders have recently emerged as one of the most common types of CMD. COL6 CMD is caused by deficiency and/or dysfunction of extracellular matrix (ECM) protein collagen VI. Currently, there is no specific treatment for this disabling and life-threatening disease. The primary cellular targets for collagen VI CMD therapy are fibroblasts in muscle, tendon and skin, as opposed to muscle cells for other types of muscular dystrophies. However, recent advances in stem cell research have raised the possibility that use of adult stem cells may provide dramatic new therapies for treatment of COL6 CMD.

Methods: Here, we developed a procedure for isolation of human stem cells from the adipose layer of neonatal skin. The adipose-derived stem cells (ADSC) were examined for expression of ECM and related genes using gene expression array analysis. The therapeutic potential of ADSC was assessed after a single intramuscular transplantation in collagen VI-deficient mice.
\end{abstract}

Results: Analysis of primary cultures confirmed that established ADSC represent a morphologically homogenous population with phenotypic and functional features of adult mesenchymal stem cells. A comprehensive gene expression analysis showed that ADSC express a vast array of ECM genes. Importantly, it was observed that ADSC synthesize and secrete all three collagen VI chains, suggesting suitability of ADSC for COL6 CMD treatment. Furthermore, we have found that a single intramuscular transplantation of ADSC into Col6a $1^{-1-}$ Rag $^{-1-}$ mice under physiological and cardiotoxin-induced injury/regeneration conditions results in efficient engraftment and migration of stem cells within the skeletal muscle. Importantly, we showed that ADSC can survive long-term and continuously secrete the therapeutic collagen $\mathrm{VI}$ protein missing in the mutant mice.

Conclusions: Overall, our findings suggest that stem cell therapy can potentially provide a new avenue for the treatment of COL6 CMD and other muscular disorders and injuries.

\section{Introduction}

Knowledge of the genetic and molecular mechanisms underlying congenital muscular dystrophies (CMDs) has dramatically advanced in the past decade [1]. However, treatment options for CMDs have remained limited and there is no cure for this group of disabling and often lethal disorders. The CMDs present with muscle pathologies

\footnotetext{
* Correspondence: Olga.lgoucheva@jefferson.edu

'Department of Dermatology and Cutaneous Biology, Jefferson Medical College, Thomas Jefferson University, BLSB, Rm. 430, 233 South 10th Street, Philadelphia, PA 19107, USA

Full list of author information is available at the end of the article
}

similar to those seen in traditional muscular dystrophies, of which Duchenne and Becker muscular dystrophies are the major forms. However, the mechanisms leading to the muscle pathologies (sarcolemma instability, degeneration and regeneration of muscle cells, apoptosis and fibrosis) differ between the common CMD types and other muscular dystrophies. Gene mutations that result in disturbed interactions between extracellular matrix (ECM) and muscle cells underlie the most prevalent CMD types, that is COL6 CMD, LAMA2 CMD or MCD1A, and various forms of $\alpha$-dystroglycanopathies [2]. 
COL6 CMD is the most or the second most common CMD type in the North American, Japanese and Northern England populations [3-5]. Disease is characterized by muscle weakness during the first two years of life [1]. Ullrich congenital muscular dystrophy (UCMD) and Bethlem myopathy, respectively, represent the severe and mild end of a clinical continuum associated with a deficiency or dysfunction of collagen type VI $[1,6]$. Patients afflicted with COL6 CMD manifest not only muscle weakness but also connective tissue abnormalities, including joint contractures and distal hypermobility. Severely affected UCMD patients are never able to walk independently and suffer from respiratory failure, resulting in early death. The disease is caused by dominant or recessive mutations in the genes encoding collagen VI subunits [1]. Collagen VI is produced by diverse connective tissue cell types in almost all organs. In the skeletal muscle, collagen VI is synthesized by muscle fibroblasts but not by muscle cells $[7,8]$. The protein is composed of different subunits and the most common form is made up of $\alpha 1(\mathrm{VI}), \alpha 2(\mathrm{VI})$ and $\alpha 3(\mathrm{VI})$ collagen chains, encoded by the COL6A1, COL6A2 and COL6A3 genes, respectively [9]. The severe UCMD phenotype is caused by either recessive or dominant negative mutations in any of the three collagen VI genes [1]. The recessive UCMD patients typically have nonsense or frameshift mutations, resulting in a complete absence or drastic reduction of the collagen VI protein [10-12]. In COL6 CMD, the proteins at fault reside outside of the muscle cells, which is in stark contrast to most other muscular dystrophies, in which the gene mutations usually involve cellular proteins produced by muscle cells. Thus, even though several therapeutic approaches have been explored for traditional muscular dystrophies, there is a need to develop treatment strategies that specifically target muscle ECM alterations.

A mouse mutant lacking the $\alpha 1(\mathrm{VI})$ collagen chain, the Col6a1 $1^{-1-}$ mouse generated by gene targeting, has served as a model for recessive UCMD [13]. Like the mouse model for Duchenne muscular dystrophy, the phenotype of the Colba1 $1^{-/-}$mice is significantly milder than that of the recessive UCMD patients with a total absence of collagen VI protein. The Col6a1 ${ }^{-/-}$mice have normal life spans and their skeletal muscles display relatively mild myopathic pathology, including variation in muscle fiber diameter and the presence of muscle fibers with centrally localized nuclei. Physiological assessment of the muscles has demonstrated a loss of contractile strength, in that tetanic and twitch tensions were significantly reduced. Myoblasts from the Col6a1 ${ }^{-/-}$mice and UCMD patients have been shown to display a latent mitochondrial dysfunction that predisposes muscle fibers to apoptosis $[14,15]$. The abnormality in mitochondria and increase in apoptosis have recently been demonstrated to result from defective autophagy [16]. This has led to a pilot treatment (one month) and a long-term trial (1 to 3.2 years) of a small number of COL6 CMD patients in Italy, using oral administration of cyclosporine A to inhibit the mitochondrial dysfunction $[17,18]$. The long-term cyclosporine A treatment was shown to be well tolerated and was able to ameliorate performance in limb muscles, but not in respiratory muscles. The results suggest that the pharmacological treatment, although promising, is not sufficient for treating the disease.

Stem cell-based therapy holds promise for treating genetic diseases and has been utilized in animal models and human clinical trials for different types of muscular dystrophies, in particular Duchenne muscular dystrophy [19]. The majority of these studies evaluated the ability of muscle-derived progenitor or stem cells as well as adult stem cells from non-muscle tissues to replace damaged muscle fibers. However, effective cellular therapy for ECM-related CMDs rests on the ability of the therapeutic cells to secrete normal ECM proteins that can prevent muscle cell degeneration rather than on the potential of these cells to differentiate into muscle fibers. Multipotent mesenchymal stem cells (MSC) were originally isolated from bone marrow and subsequently from many other adult tissues. MSC display extensive proliferation capacity in culture and can differentiate in vitro into various connective tissue cell types [20,21]. These unique features make MSC an attractive therapeutic option for COL6 CMD. Although bone marrow is the main source for MSC isolation, subcutaneous fat represents an alternative repository for stem cells and is currently a subject of intensive investigations [22]. Similarly to bone marrow-derived MSC, adipose-derived stem cells (ADSC) can be induced to differentiate into multiple lineages in vitro under adipogenic, osteogenic, chondrogenic, myogenic and neurogenic supplementation conditions [23]. Furthermore, ADSC can be obtained by less invasive methods, have relatively lower donor-site morbidity and are available in large quantities for procurement [24]. Also, ADSC have immunoprivileged behavior in immunocompetent mouse models, suggesting their potential as immunopriviledged universal cells with the capacity to be used in the allogeneic setting and to reduce graft-versus-host disease [24].

In this study, we developed a procedure for the isolation of ADSC from human neonatal foreskin and demonstrated that the established primary cultures represent a cell population with phenotypic and functional features of mesenchymal progenitors. We also showed that ADSC cultured in vitro secrete a variety of ECM proteins, including collagen VI and, therefore, can provide therapeutic ECM proteins without cell differentiation in the muscle environment. In addition, we explored for the first time the potential of xenogeneic ADSC in treating COL6 CMD using $\mathrm{Col}_{\mathrm{C} a 1^{-/-}}$mice, the animal model for recessive 
UCMD. Our results show that ADSC delivered intramuscularly are engrafted in the interstitial connective tissues of the skeletal muscle where they continued to secrete collagen VI and assemble collagen VI microfibrils. The number of collagen VI positive myofibers increased steadily over time after transplantation. The extent of ADSC engraftment and collagen VI production was significantly higher when muscle was injured by cardiotoxin. Our study provides the proof-of-concept evidence that ADSC therapy has the potential to treat COL6 CMD.

\section{Methods}

\section{Mouse strains}

The Colba1 $1^{-/-}$mice have been described previously [13]. Immunocompromised Col6a1 $1^{-1-}$ mice were generated by

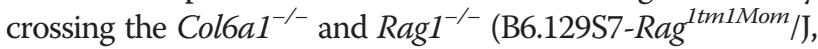
Jackson Laboratory, Bar Harbor, ME, USA) mice. The Col6a1 ${ }^{-/-} \mathrm{Rag1}^{-/-}$genotype was selected by PCR. Col6a1 ${ }^{-/} \mathrm{Rag1}^{-/-}$mice were used in all ADSC transplantation studies to avoid possible rejection of human cells.

\section{Isolation of adipose-derived stem cells from human neonatal foreskin and tissue culture conditions}

Human adipose-derived stem cells were isolated from discarded neonatal foreskin. The study was not classified as human subject research as per guidelines of the Thomas Jefferson University IRB and as such did not require ethics approval. The use of discarded tissue for research purpose does not require patient informed consent, the hospital's general informed consent for surgery/procedures specifies that the removed tissue may be collected anonymously and used for research. Briefly, tissue samples were washed two times in PBS plus 1\% Penicillin/Streptomycin (Gibco, Grand Island, NY, USA) and then the adipose tissue was separated from the connective tissue using a surgical blade. The tissue was minced and digested in collagenase solution (0.001 g collagenase I (Sigma, St. Louis, MO, USA) in $1 \mathrm{ml}$ PBS and BSA). To obtain a single cell suspension, the digested tissue was applied to a $30 \mu \mathrm{m}$ mesh separation filter (Miltenyi Biotec, Auburn, CA, USA). A PBS plus 1\% BSA solution was added to the mesh to quench the enzyme and flush any remaining cells through the filter. The suspension was centrifuged and the pellet was resuspended in $1 \mathrm{ml}$ of (D)MEM/F12 and GlutaMax ${ }^{\text {Ta }}$ plus $10 \%$ fetal bovine serum (FBS) (Gibco). Cells were plated in (D)MEM/F12 and GlutaMax ${ }^{\mathrm{Tw}}$ plus $10 \%$ FBS (Invitrogen, Grand Island, NY, USA) and grown to confluence. To remove hematopoietic cells, cells were then depleted using magnetic separation beads. For immunodepletion, the cell pellet was resuspended in $40 \mu \mathrm{l}$ PBS plus $0.5 \%$ BSA plus $2 \mathrm{mM}$ ethylenediaminetetraacetic acid (EDTA) (depletion buffer), then $20 \mu \mathrm{l}$ of CD45 microbeads (Miltenyi Biotec), $20 \mu \mathrm{l}$ of FcR blocking reagent (Miltenyi Biotec) and $20 \mu \mathrm{l}$ of CD31 microbeads (Miltenyi Biotec) were added. The cells were incubated on ice for $15 \mathrm{mi}-$ nutes. The cells were washed with depletion buffer and centrifuged. The cell pellet was resuspended in depletion buffer and applied to the MiniMACS magnetic field column system (Miltenyi Biotec) using the MACS MS separation column (Miltenyi Biotec). The eluted cells were collected after several washes and centrifugation. The collected cells were designated as first passage cells and were cultured in (D)MEM/F12 and GlutaMax ${ }^{\mathrm{Tm}}$ plus 10\% FBS at $37^{\circ} \mathrm{C}$ in a humidified $5 \% \mathrm{CO}_{2}-95 \%$ air atmosphere.

\section{Fluorescence-activated cell sorting analysis}

ADSC were grown until confluent, trypsinized and pelleted by centrifugation at $200 \mathrm{~g}$ for five minutes. For fluorescenceactivated cell sorting (FACS) analysis, approximately $2.5 \times$ $10^{5}$ cells were resuspended in $100 \mu \mathrm{l} \mathrm{FACS}$ buffer containing $10 \%$ FBS in PBS. For FACS analysis of surface markers, each sample was incubated for 30 minutes at $4{ }^{\circ} \mathrm{C}$ with fluorescein isothiocyanate (FITC)- or phycoerythrin (PE)-conjugated antibodies against the following surface markers: CD45, CD34, CD11b, CD31, CD19, CD90, CD44, CD71, CD29, CD73, STRO-1, HLA-ABC, HLA-DR, CD117, CD105, CD106 (eBioscience, San Diego, CA, USA) according to the manufacturer's instructions. After incubation, the labeled cells were diluted with $2 \mathrm{ml}$ of FACS buffer, pelleted and resuspended in $500 \mu \mathrm{l}$ of FACS buffer. Generally, approximately $10^{4}$ cells were analyzed per sample using the BD FACSCalibur flow cytometer (BD Biosciences, San Jose, CA, USA). Results were analyzed using FlowJo software.

\section{Differentiation assays}

Before addition of inductive media, ADSC cultures were grown to confluence after which the standard adipose stem cell medium was replaced with the inductive media. Osteogenic differentiation was induced by culturing cells with osteoinductive medium (Lifeline Cell Technology, Frederick, MD, USA). The cells were treated with osteogenic supplements for up to five weeks with three medium changes per week. Cells were morphologically examined and assessed for alkaline phosphatase (ALP) activity and ECM calcification. Analysis of ALP activity was done using the ALP Semiquantitative Histochemical Diagnostic Kit (Sigma). For matrix mineralization, three-week osteogenic cultures were fixed with $100 \%$ ethanol and analyzed using 2\% Alizarin Red Stain (Lifeline Cell Technology). Cultures were also analyzed for mRNA transcripts of $A L P$ and $B G L A P / O C N$, which denote markers of a mature osteoblast. Total RNA was isolated as described below and subjected to RT-PCR amplification using gene-specific primers listed in Additional file 1: Table S1.

To induce adipocytic differentiation, cells were cultured in adipogenic induction medium (Lifeline Cell Technology) for five weeks with three medium changes per week. For histochemical examination, adipogenic 
cultures were stained for the presence of intracellular lipid droplets using Oil Red-O staining as an indicator of intracellular lipid accumulation. Briefly, cells were fixed for 30 minutes in $4 \%$ paraformaldehyde (Lifeline Cell Technology), washed with 100\% 1,2-propanediol dehydration solution (Lifeline Cell Technology) and then stained for 30 minutes at $37^{\circ} \mathrm{C}$ with $0.5 \%$ Oil Red-O solution (Lifeline Cell Technology). Adipogenic cultures were also analyzed for mRNA transcripts of $L P L$, expressed in preadipocytic as well as adipocytic cells and $P P A R Y 2$, a transcription factor expressed in mature adipocytes. The gene-specific primers are listed in Additional file 1: Table S1.

Chondrogenic differentiation was performed using the micromass culture technique. Briefly, $10 \mathrm{ml}$ of a concentrated cell suspension, at least $1 \times 10^{6}$ cells, were plated into the center of each well of a 96-well plate and allowed to attach at $37^{\circ} \mathrm{C}$ for two hours. Chondrogenic medium (Cambrex, East Rutherford, NJ, USA) was gently overlaid so as not to detach the cells nodules. Cultures were maintained in chondrogenic medium for up to five weeks with three medium changes per week. Sulfated proteoglycans were specifically detected using Alcian blue staining under acidic conditions. Briefly, cell nodules were fixed with $10 \%$ formalin for 20 minutes and washed extensively with PBS. Fixed cells were then incubated for 30 minutes with 1\% (w/v) Alcian blue (Sigma) in $0.1 \mathrm{M} \mathrm{HCl}$ at $\mathrm{pH} 1.0$ and washed with $0.1 \mathrm{M} \mathrm{HCl}$ for five minutes to remove excess stain. Chondrogenic cultures were also analyzed for mRNA transcripts of SOX9, COLII, $C O L X, C O L X I$ and ACAN/AGN. Gene-specific primers are listed in Additional file 1: Table S1.

\section{Gene expression analysis of stem cells}

Total RNA from ADSC was isolated using the Qiagen RNeasy Mini Kit (Qiagen, Valencia, CA, USA). A whole human genome oligo microarray (one-color) (Agilent Technologies, Santa Clara, CA, USA) was performed by a service provided by Miltenyi Biotec. Briefly, the RNA was amplified and labeled with $\mathrm{Cy} 3$ using the Agilent Low Input Quick Amp Labeling Kit (Agilent Technologies) according to the manufacturer's protocol. The hybridization was performed according to the Agilent 60-mer oligo microarray processing protocol using the Agilent Gene Expression Hybridization Kit (Agilent Technologies). All steps including amplification, labeling and hybridization were performed as a service by Miltenyi Biotec. Fluorescence signals of the hybridized Agilent Microarrays were detected using Agilent's Microarray Scanner System (Agilent Technologies). The differential gene expression data were analyzed using the Rosetta Resolver ${ }^{\circ}$ gene expression data analysis system (Rosetta Biosoftware). The complete microarray data are available at the National Center for Biotechnology
Information (NCBI) Gene Expression Omnibus (GEO) repository under Series Accession Number GSE51030.

\section{RNA isolation and RT-PCR analysis}

Total RNA was isolated using the Qiagen RNeasy Mini Kit (Qiagen). RT-PCR was conducted using the Verso 1-Step RT-PCR ReddyMix Kit (Thermo Scientific, Waltham, MA, USA). For a standard reaction, $50 \mathrm{ng}$ of total RNA was mixed together with $200 \mathrm{nM}$ each of primers in a final volume of $25 \mu \mathrm{l}$. All primers and melting temperatures $(\mathrm{Tm})$ used in the study are listed in Additional file 1: Table S1. The amplification cycles for PCR were $50^{\circ} \mathrm{C}$ for 15 minutes, $95^{\circ} \mathrm{C}$ for 2 minutes, followed by 35 cycles of $95^{\circ} \mathrm{C}$ for 20 seconds, 50 to $60^{\circ} \mathrm{C}$ for 30 seconds and $72^{\circ} \mathrm{C}$ for 1 minute, followed by an additional extension for 5 minutes at $72^{\circ} \mathrm{C}$. The amplified fragments were separated on $1.5 \%$ agarose gel in $1 \times$ Trisacetate EDTA (TAE) buffer at $100 \mathrm{~V}$ for one hour and visualized with ethidium bromide staining on a GelDoc 1000 (BioRad, Hercules, CA, USA).

\section{Western blot analysis}

Denatured proteins were isolated from ADSC. Proteins were separated by a $4 \%$ to $12 \%$ gradient SDS-polyacrylamide gel electrophoresis (PAGE) and transferred to a polyvinylidene difluoride (PVDF) membrane followed by the Western blot analysis using polyclonal anti-COL6A1 [25], anti-COL6A2 [26] and anti-COL6A3 antibodies [27]. Immunocomplexes were detected by using horseradish peroxidase (HRP)-labeled anti-rabbit secondary antibodies (Promega, Madison, WI, USA) and visualized by using SuperSignal WestFemto substrates (Pierce, Rockford, IL, USA).

\section{Indirect immunofluorescent analysis}

For indirect immunofluorescent analysis, cells cultured in chamber slides (Nalgen/Nunc, Rochester, NY, USA) were fixed with methanol at $-20^{\circ} \mathrm{C}$ and blocked with $1 \%$ BSA in PBS for one hour at room temperature. Proteins were detected with primary antibodies generated against collagen VI $\alpha 1, \alpha 2$ and $\alpha 3$ chains (1:1000 dilutions), respectively, for one hour at room temperature. Immunocomplexes were detected with AlexaFluor ${ }^{488}$. or AlexaFluor ${ }^{594}$-conjugated secondary antibodies (Invitrogen) at a dilution of 1:200 for one hour incubation at room temperature. To visualize nuclei, slides were counterstained with 4',6-diamidino-2-phenyl indol (DAPI; 1:1000 dilution) for two minutes at room temperature. Slides were then covered with Fluorosafe reagent and immunofluorescent images were obtained on a Nikon TS100F fluorescent microscope. 


\section{Transplantation of ADSC into Col6a $1^{-/-} \mathrm{Rag}^{-/-}$mice under physiological and CTX-induced injury/regeneration conditions}

All animal procedures were performed in accordance with the Guide for the Care and Use of Laboratory Animals (National Institutes of Health publication no. 86-23) and approved by the Institutional Animal Care and Use Committee of the Thomas Jefferson University. For all transplantation studies, ADSC (passage 2 to 4) were labeled with a red lipophilic tracer, DiOC18 (Molecular Probes, Grand Island, NY, USA). For therapeutic assessment of ADSC in physiological conditions, neonatal three- to five-day-old Col6a1 ${ }^{-/}$Rag1 $^{-/-}$mice ( $n=5 /$ treatment/time point) were intramuscularly transplanted with $0.5 \times 10^{6}$ DiOC18-ADSC in $50 \mu \mathrm{l}$ PBS in the gastrocnemius muscle (GCM) of the left hindlimb. The right hindlimb was injected with PBS and served as a control. To induce muscle injury, Col6a1 ${ }^{-/}$Rag1 $^{-/-}$mice $(\mathrm{n}=5 /$ treatment/ time point) were injected with $10 \mu \mathrm{M}$ cardiotoxin (CTX, Sigma) dissolved in PBS in the GCM of the left hindlimb two days after transplantation. The right GCMs were injected with PBS and used as a control. For analysis, transplanted mice were euthanized by $\mathrm{CO}_{2}$ inhalation at predetermined time points (one, two, three, four and six weeks) and muscle samples were collected. In vivo imaging (IVIS) (Lumina XR, Caliper LifeSciences, Hopkinton, MA, USA) was performed at indicated time points to determine the localization of the transplants. Transplantation was evaluated by histopathologic, indirect immunofluorescence and molecular analyses. For all histopathologic analyses, collected tissue samples were embedded into optimal cutting temperature (OCT) compound (VWR, Pittsburgh, PA, USA), frozen and cryosections taken at a thickness of $10 \mu \mathrm{m}$. For histological analysis, sections were stained with $\mathrm{H} \& \mathrm{E}$ using a standard protocol. All samples were evaluated for the presence of engrafted DiOC18ADSC expressing cells using fluorescence microscopy. For indirect immunofluorescent analysis of collagen VI, crosssections were stained with anti- $\alpha 1(\mathrm{VI})$ collagen rabbit polyclonal antibodies. Immunocomplexes were detected with AlexaFluor ${ }^{488}$ - or AlexaFluor ${ }^{594}$-labeled secondary antibodies (Invitrogen). For the analysis of co-localization of type VI collagen and lamin A/C-positive ADSC, muscle sections were stained with human specific monoclonal antibodies to lamin A/C (Millipore/Chemicon, Billerica, MA, USA) and AlexaFluor ${ }^{488}$-labeled anti-mouse immunoglobulin secondary antibodies (Invitrogen). For the analysis of co-localization of type VI and IV collagens, sections were stained with antibodies specific to type IV collagen (Millipore/Chemicon) and AlexaFluor $^{594}$ - or AlexaFluor ${ }^{350}$ labeled secondary antibodies (Invitrogen). To examine immune response, macrophages were detected with FITC-conjugated anti-mouse CD11b (BD Bioscience). Pax7-positive satellite cells were detected using anti-Pax7 (Developmental Studies Hybridome Bank, Iowa City, IA, USA). Images were taken and analyzed using AutoQuant imaging software (AutoQuant Imaging Inc, Troy, NY, USA). The relative number of the engrafted lamin $\mathrm{A} / \mathrm{C}$-positive ADSC on cryosections was determined by semi-quantitative immunofluorescence analysis using AutoQuant imaging software. The average number of collagen $\alpha 1(\mathrm{VI})$-positive fibers was calculated and compared between samples collected at different time points. Multiple adjacent sections were analyzed within 20 random, non-overlapping microscopic fields per sample. All morphometric comparisons are presented as percentages of untreated limb (baseline control) and analyzed for statistical significance using the Student's t test, with $P$ value less than 0.01 considered significant in all tests.

\section{Results}

Isolation and characterization of human adipose-derived stem cells

We developed a novel method for the isolation of ADSC from the neonatal skin discarded after newborn circumcision using negative immunodepletion with a cocktail of biotinlabeled lineage-specific antibodies and magnetic cell sorting. The original cultures of ADSC were produced as described in the Methods section. Routinely, approximately $1 \times 10^{6}$ ADSC were produced from each skin sample after tissue digestion followed by negative selective depletion of mature hematopoietic cells, such as T cells, B cells, monocytes/macrophages, granulocytes, erythrocytes and their committed precursors. The ADSC appeared initially as adherent, spindle-shaped cells after three to four days of culture. Then, the cells grew rapidly, and could be easily expanded.

To determine the antigen expression profile of the established ADSC, immuno-phenotypic analysis (FACS) using fluorescently labeled antibodies against a panel of cell surface markers was performed (Figure 1A). The analysis showed that the cells do not express endothelial markers (CD31-PECAM1), hematopoietic markers (CD34, CD45 and CD117-c-kit) or the marker for macrophages (CD11b). However, the cells expressed high levels of CD44, CD105 (SH2), adhesion markers (CD29-integrin $\beta 1$ and CD90-Thy-1) and mesenchymal stem cell marker CD73, consistent with the published profile from adult adipose tissues. Also, the ADSC were negative for HLA-class II (HLA-DR), but positive for HLA-class I (HLA-ABC).

To verify the ability of the generated ADSC cultures to differentiate into multiple cell types, the cells were analyzed for osteogenic, adipogenic and chondrogenic potentials in vitro. To induce osteogenic differentiation, the cells were maintained in differentiation basal osteogenic medium for up to five weeks. Cell cultures were morphologically examined and ALP activity and ECM calcification were assessed. As expected, the cells underwent 


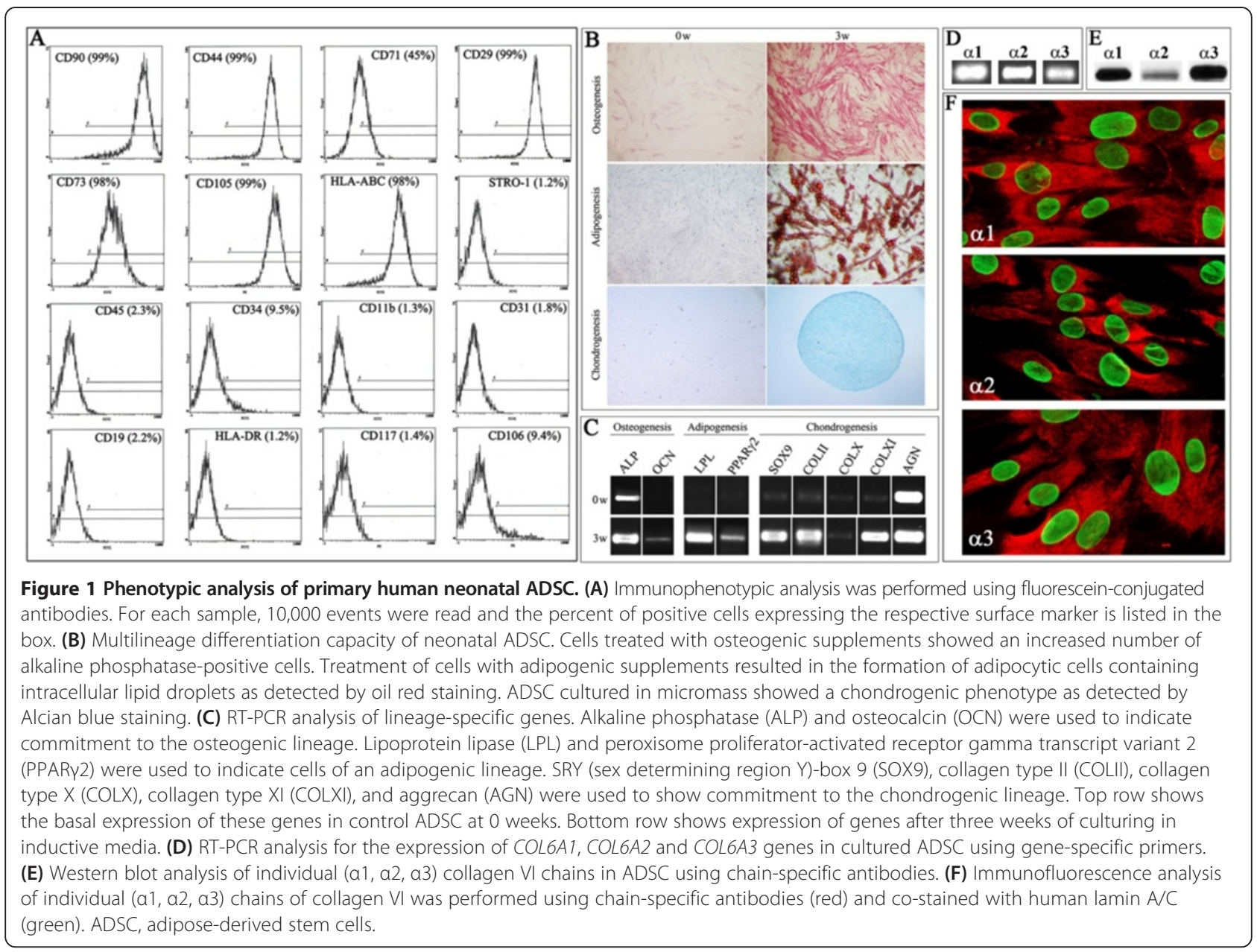

a dramatic change in cellular morphology from spindleshaped to cuboidal. In addition, histochemical analysis of the cells for ALP activity showed a high and uniform staining (Figure 1B). When the cultures were examined for their ability to elaborate a mineralized ECM, a substantial calcium deposition was detected, while no calcium deposition was seen in control ADSC cultures (data not shown). To verify these data, mRNA expression of the osteogenic markers, such as ALP and osteocalcin (OCN), was also investigated. As expected, cells under differentiation conditions showed substantial up-regulation of the indicated osteogenic marker genes (Figure $1 \mathrm{C}$ ), although a low-level $A L P$ expression could be detected in control non-differentiated cultures.

To induce adipocytic differentiation, cells were maintained in adipogenic induction medium for five weeks. For histochemical examination, the adipogenic culture was stained for the presence of intracellular lipid droplets as an indicator of intracellular lipid accumulation. Oil Red-O staining of five-week cultures for intracellular lipid vacuoles did not show any cells resembling adipocytes in control cultures, whereas upon treatment with adipogenic inductive medium, cells with a typical adipocyte phenotype containing intracellular lipid droplets appeared (Figure 1B). Moreover, RT-PCR analysis showed that adipocyte-related transcripts, such as lipoprotein lipase $(L P L)$ and peroxisome proliferator-activated receptor $\gamma^{2}(P P A R \gamma 2)$, were induced in differentiated ADSC (Figure 1C).

Chondrogenic differentiation was performed using the micromass culture technique in which cellular condensation (a critical first event of chondrogenesis) is duplicated. Chondrogenic medium was gently overlaid so as not to detach the cell nodules and the cultures were maintained for up to five weeks. Under these conditions, the cells formed nodules associated with a well-organized ECM rich in sulfated proteoglycans as detected using Alcianblue staining under acidic conditions (Figure 1B). Nodules were associated with an Alcian-blue-positive ECM, indicative of the presence of sulfated proteoglycans within the matrix, whereas no obvious staining was observed in undifferentiated control ADSC cultures. Next, cell aggregates were analyzed by RT-PCR using specific primers for chondrogenic-related genes. As expected, aggregated 
cultures showed a marked induction of mRNAs from chondrogenic genes, including SOX9 (Figure 1C). In addition, expression levels of $C O L 2 A 1$ and $C O L 11 A 1$ genes were also significantly increased. Overall, our data indicate that the neonatal ADSC generated here represent a morphologically homogenous population with phenotypic and functional features of adult mesenchymal stem cells and possess the capacity to differentiate toward specific lineages when exposed to the appropriate inductive media.

\section{Differential expression of ECM and related genes in ADSC}

To examine the expression profile of the established ADSC, we performed a whole human genome oligo microarray analysis with a special emphasis on ECM, adhesion molecules and related genes. The median standard deviation of identified genes across three replicates was about 0.04 , indicating good intra-array reproducibility. Transcriptional activity was identified in all categories of genes expressed by ADSC, including collagens, ECM and basement membrane constituents, adhesion molecules involved in cell-cell and cell-matrix interactions, and proteases involved in degradation of the ECM and their inhibitors (Table 1 and Additional file 2: Table S2). High expression of several collagen genes was detected, including those coding for the $\alpha 1$ and $\alpha 2$ chains of collagen I, the $\alpha 2$ chain of collagen IV, the $\alpha 1$ and $\alpha 2$ chains of collagen $\mathrm{V}$, the $\alpha 1$ and $\alpha 2$ chains of collagen VI, the $\alpha 1$ chain of collagen XII, and the $\alpha 1$ chain of collagen XVI. Transcripts for many other collagens were also detectable. Moreover, relatively high expression of several basement membrane constituents was identified, such as the $L A M B 1, L A M B 2$ and $L A M C 1$. In addition, other genes with significant roles in ECM integrity were identified, such as the decorin $(D C N$, affects the fate of collagen fibril formation), lumican (LUM, regulates collagen fibril assembly) and elastin (ELN, the major component of elastic fibers, provides strength and flexibility to connective tissue). Among cell-matrix adhesion molecules detected were different integrins (ITGA5, ITGA7, ITGAV, ITGB1 and $I T G B 5)$ and the immunoglobulin superfamily genes (ICAM1, ICAM2 and ICAM3). The obtained transcriptional signatures also showed that ADSC express different transmembrane molecules, with the highest expression of the cadherin $2(C D H 2)$ and to a lesser extent $C D H 11$, $\mathrm{CDH} 13$ and $\mathrm{CHD} 22$. Several genes participating in ECM remodeling, including matrix metallopeptidases (MMP1 and MMP3) and metallopeptidase inhibitors (TIMP1, TIMP2 and TIMP3), were highly expressed in ADSC. Interestingly, the expression analysis of genes coding for myogenic markers showed that ADSC were negative for the majority of them, including myogenin, Myf5, MRF4, MyoD, Pax7 and M-cadherin. However, the analysis revealed that ADSC express a relatively high level of desmin (DES, helps maintain the structure of sarcomeres, which are necessary for muscle contraction) and low expression of the myocyte-specific enhancer factor $2 \mathrm{C}(M E F 2 C$, plays a role in myogenesis and, possibly, in maintaining the differentiated state of muscle cells) and dystrophin (DMD, acts as an anchor for muscle fibers and protects them from injury). Taken together, our analysis shows that neonatal ADSC express a plethora of different ECM, adhesion molecules and other ECMrelated genes.

Our gene expression analysis demonstrated that out of all collagen types detected in ADSC, collagen type VI (COL6A1, in particular) is the second most expressed gene after type I collagen (COL1A1 and COL1A2). To further verify these data, expression of all three individual chains of collagen VI in established ADSC was confirmed by RT-PCR, western blot and immunofluorescence. The presence of COL6A1, COL6A2 and COL6A3 transcripts and proteins was detected using chain-specific primers and antibodies (Figure 1D and E), respectively. These results were further confirmed by indirect immunofluorescence analysis (Figure 1F). Overall, our data demonstrate that neonatal ADSC produce a significant level of collagen type VI and are readily available for therapeutic protein replacement in COL6 CMD.

\section{Intramuscular transplantation of ADSC into Col6a $1^{-/-} \mathrm{Rag}^{-/-}$mice under physiological conditions} In order to assess the potential of neonatal ADSC in therapeutic application of COL6 CMD, fluorescently labeled ADSC (DiOC18-ADSC) were intramuscularly transplanted into the GCM of the left hindlimb of threeto five-day-old Col6a1 $1^{-/-} \mathrm{Rag1}^{-/-}$mice. The right limb was injected with PBS and served as internal control. Live imaging of both transplanted and control mouse limbs was performed every week for six weeks using the IVIS imaging system. To measure myofibers associated with immunoreactive $\alpha 1$ (VI) collagen and estimate the engraftment level of donor cells in recipient muscle tissue, the cryosections with positive DiOC18-ADSC were coimmunostained with antibodies against $\alpha 1(\mathrm{VI})$ collagen and lamin $\mathrm{A} / \mathrm{C}$ as a marker for donor human cells. As shown in Figure 2A, the red fluorescent signals of DiOC18-labeled ADSC were detectable in all transplanted limbs throughout the study but not in the control hindlimbs. Based on morphometric analysis, the GCM receiving an ADSC transplant showed extensive engraftment as judged by the presence of lamin $\mathrm{A} / \mathrm{C}$-positive cells on muscle cryosections (Figure 2B). Moreover, we found that the level of engraftment did not change significantly and sustained at the level of $20 \%$ up to six weeks after transplantation. Analysis of the transplanted GCM of recipient limbs revealed a robust, time-dependent engraftment and distribution of collagen VI-positive myofibers (Figure 3). It is interesting to note that during the first week after 
Table 1 Differential expression analysis in primary human neonatal ADSC

Gene symbol RefSeq number Description

Signal Fold difference gene/GAPDH ${ }^{\mathrm{a}}$

Extracellular matrix proteins

Collagens and ECM structural constituents

\begin{tabular}{|c|c|c|c|}
\hline COL1A1 & NM_000088 & Homo sapiens collagen, type I, alpha 1 & 183526 \\
\hline COL1A2 & NM_000089 & Homo sapiens collagen, type I, alpha 2 & 142138 \\
\hline COL3A1 & NM_000090 & Homo sapiens collagen, type III, alpha 1 & 3108 \\
\hline COL4A1 & NM_001845 & Homo sapiens collagen, type IV, alpha 1 & 5622 \\
\hline COL4A2 & NM_001846 & Homo sapiens collagen, type IV, alpha 2 & 44164 \\
\hline COL5A1 & NM_000093 & Homo sapiens collagen, type $V$, alpha 1 & 32129 \\
\hline COL5A2 & NM_000393 & Homo sapiens collagen, type $V$, alpha 2 & 19919 \\
\hline COL6A1 & NM_001848 & Homo sapiens collagen, type Vl, alpha 1 & 117011 \\
\hline COL6A2 & NM_058174 & Homo sapiens collagen, type VI, alpha 2 & 11593 \\
\hline COL6A3 & NM_004369 & Homo sapiens collagen, type VI, alpha 3 & 1112 \\
\hline COL7A1 & NM_000094 & Homo sapiens collagen, type VII, alpha 1 & 1136 \\
\hline COL12A1 & NM_004370 & Homo sapiens collagen, type XII, alpha 1 & 17353 \\
\hline COL16A1 & NM_001856 & Homo sapiens collagen, type XVI, alpha 1 & 17366 \\
\hline DCN & NM_001920 & Homo sapiens decorin & 22826 \\
\hline FN1 & NM_054034 & Homo sapiens fibronectin 1 & 6213 \\
\hline \multirow[t]{2}{*}{ LUM } & NM_002345 & Homo sapiens lumican & 7747 \\
\hline & \multicolumn{3}{|c|}{ Basement membrane constituents } \\
\hline LAMA2 & NM_000426 & Homo sapiens laminin, alpha 2 & 804 \\
\hline LAMB1 & NM_002291 & Homo sapiens laminin, beta 1 & 10371 \\
\hline LAMB2 & NM_002292 & Homo sapiens laminin, beta 2 (laminin S) & 16172 \\
\hline LAMC1 & NM_002293 & Homo sapiens laminin, gamma 1 (formerly LAMB2) & 10072 \\
\hline
\end{tabular}

\section{Cell adhesion molecules}

Cell-matrix adhesion

$\begin{array}{lll}\text { ITGA5 } & \text { NM_002205 } & \begin{array}{l}\text { Homo sapiens integrin, alpha } 5 \text { (fibronectin receptor, alpha } \\ \text { polypeptide) }\end{array} \\ \text { ITGA6 } & \text { NM_000210 } & \text { Homo sapiens integrin, alpha 6 } \\ \text { ITGA7 } & \text { NM_002206 } & \begin{array}{l}\text { Homo sapiens integrin, alpha 7 } \\ \text { ITGB1 }\end{array} \\ \text { NM_133376 } & \begin{array}{l}\text { Homo sapiens integrin, beta 1 (fibronectin receptor, beta polypeptide, } \\ \text { antigen CD29 includes MDF2, MSK12) }\end{array} \\ \text { ITGB5 } & \text { NM_002213 } & \text { Homo sapiens integrin, beta 5 }\end{array}$

$3324 \quad 0.04$

$1168 \quad 0.01$

$7553 \quad 0.08$

$6616 \quad 0.07$ (

$4324 \quad 0.05$

\section{ECM proteases and protease inhibitors}

$\begin{array}{lllll}\text { MMP1 } & \text { NM_002421 } & \text { Homo sapiens matrix metallopeptidase 1 (interstitial collagenase) } & 4368 & 0.05 \\ \text { TIMP1 } & \text { NM_003254 } & \text { Homo sapiens TIMP metallopeptidase inhibitor 1 } & 42809 & 0.48 \\ \text { TIMP2 } & \text { NM_003255 } & \text { Homo sapiens TIMP metallopeptidase inhibitor 2 } & 83481 & 0.93 \\ \text { TIMP3 } & \text { NM_000362 } & \text { Homo sapiens TIMP metallopeptidase inhibitor 3 } & 36463 & 0.41 \\ & & & \text { Non-muscle and muscle markers } & 0.09 \\ \text { DES } & \text { NM_001927 } & \text { Homo sapiens desmin } & 8119 & 0.38 \\ \text { MYO1C } & \text { NM_033375 } & \text { Homo sapiens myosin IC } & 33956 & 0.14\end{array}$


Table 1 Differential expression analysis in primary human neonatal ADSC (Continued)

\begin{tabular}{|c|c|c|c|c|}
\hline MYLK & NM_053025 & Homo sapiens myosin light chain kinase & 18846 & 0.21 \\
\hline MYH9 & NM_002473 & Homo sapiens myosin, heavy chain 9, non-muscle & 15884 & 0.18 \\
\hline MYL6 & NM_079423 & $\begin{array}{l}\text { Homo sapiens myosin, light chain } 6 \text {, alkali, smooth muscle and } \\
\text { non-muscle }\end{array}$ & 51777 & 0.58 \\
\hline
\end{tabular}

a The fold difference represents the ratio of intensity of each gene hybridized with the RNA isolated from hADSC normalized to the intensity of GAPDH gene. Each array was processed in an identical manner and the number represents an average of triplicate experiments from three independent cell isolates. Each gene is demarcated by the Genbank accession number, the description of the gene and the common name. Genes are grouped by their distinct functional categories. ADSC, adipose-derived stem cells; ECM, extracellular matrix.

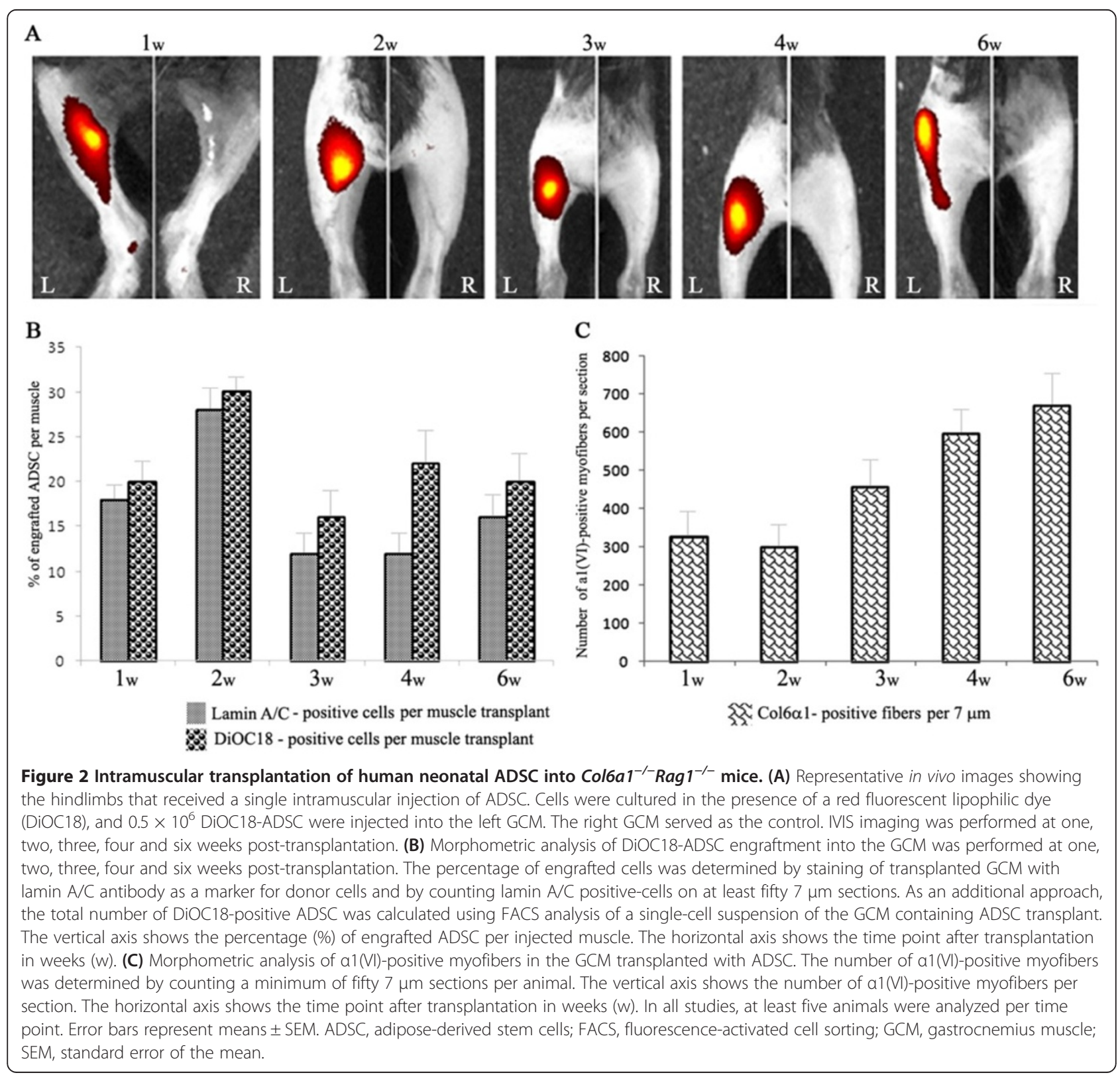




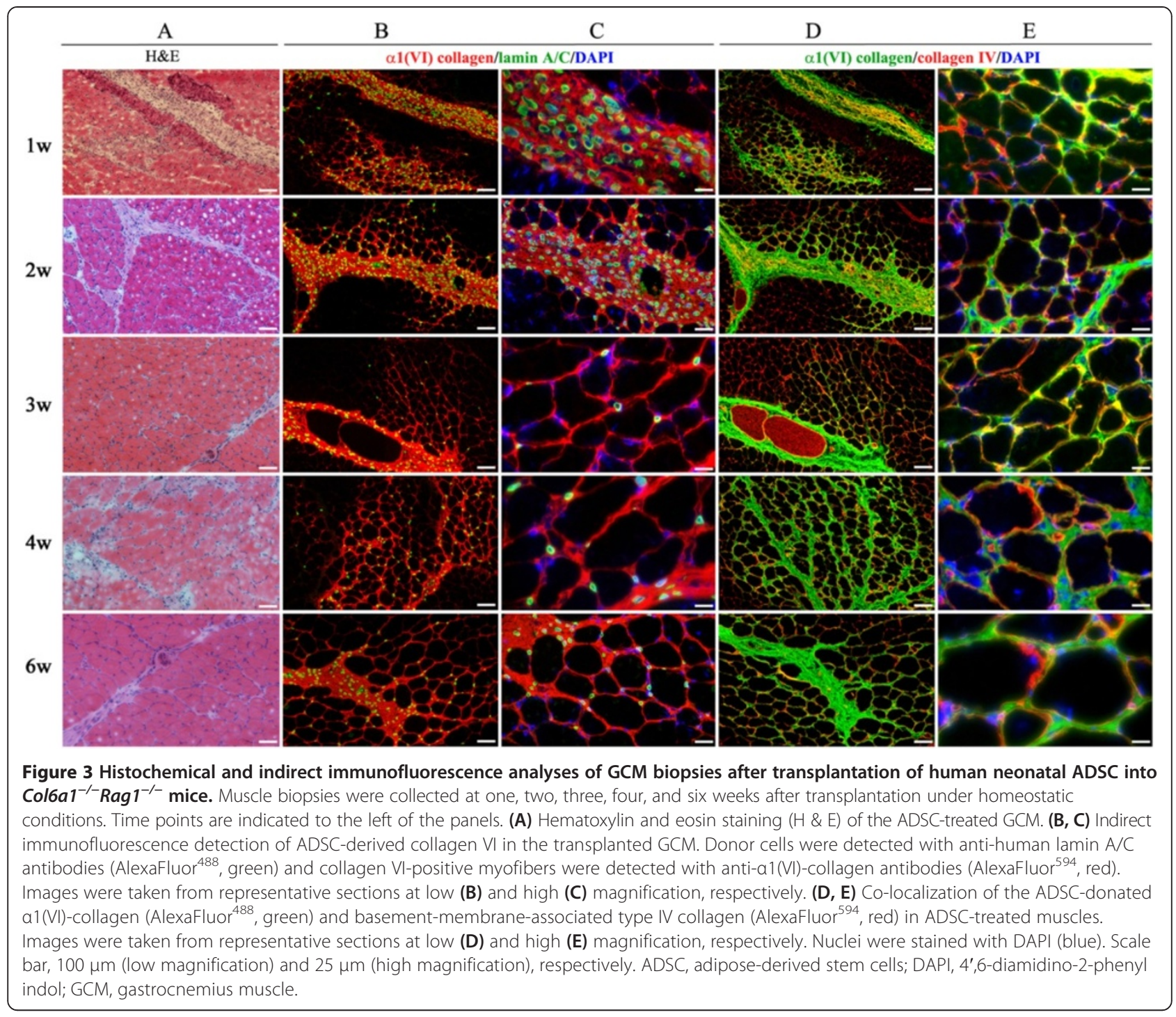

transplantation the ADSC were preferentially found in the connective tissue of perimysium and the periphery of muscle fascicles with occasional cells in endomysial space. Furthermore, the presence of an excessive number of transplanted cells during initial engraftment stages resulted in substantial enlargement of perimysial space and significant production of collagen VI into adjacent tissue. Remarkably, in the next two to six weeks, prominent and continuous collagen VI staining was strongly associated with endomysial connective tissue and many surrounding individual myofibers, although, some transplanted cells continued to reside in the perimysium space (Figure 3B and $\mathrm{C}$ ). The majority of the ADSC was able to migrate from primary perimysial residence to distal sites along endomysium, possibly in response to microenvironmental cues, and continued to donate therapeutic collagen VI protein to surrounding myofibers. In addition, the ADSC were positioned in close proximity to neighboring interstitial fibroblasts. Morphometric analysis showed a marked increase (two-fold) in $\alpha 1$ (VI) collagen-positive myofibers at the sixth week as compared to the first week of transplantation (Figure 2C). It is well known that secreted collagen VI molecules form an extended microfilament network particularly abundant close to the cells, which has been suggested to play a role in anchoring the basement membrane of non-epithelial cells to the underlying connective tissue. Using double immunostaining with antibodies specific for type IV collagen, which is an integral component of the basement membrane, and $\alpha 1$ (VI) collagen, we showed overlapping fluorescent signals of both proteins at the basement membrane of individual myofibers, suggesting functionality of the ADSC-secreted collagen VI protein (Figure 3D and E). Colba1 ${ }^{-/-}$mice homozygous for the Rag1 mutation are immunodeficient as they completely lack mature B and $\mathrm{T}$ lymphocytes but they display other fully functional 
inflammatory cells. To test whether transplantation with the ADSC resulted in any immune recognition, inflammatory cell infiltration was assessed by staining muscle tissue with $\mathrm{CD} 11 \mathrm{~b}$, as a marker for macrophages, and lamin $\mathrm{A} / \mathrm{C}$, as a marker for donor cells. As seen in Figure 4A, a similar degree of infiltration by CD11b-positive cells was found in both untreated and ADSC-treated muscle. Overall, our data indicate that
ADSC have engrafted, migrated and produced therapeutic collagen VI protein in muscle of Colba1 ${ }^{-/-} \mathrm{Rag1}^{-/-}$mice.

\section{Intramuscular transplantation of ADSC into}

Col6a $1^{-/}$Rag $1^{-/-}$mice under injury/regeneration conditions Since the muscle phenotype of the Col6a1 $1^{-/-}$mice is much milder than that of human patients, we used cardiotoxin (CTX) to injure the GCM muscle of the neonatal

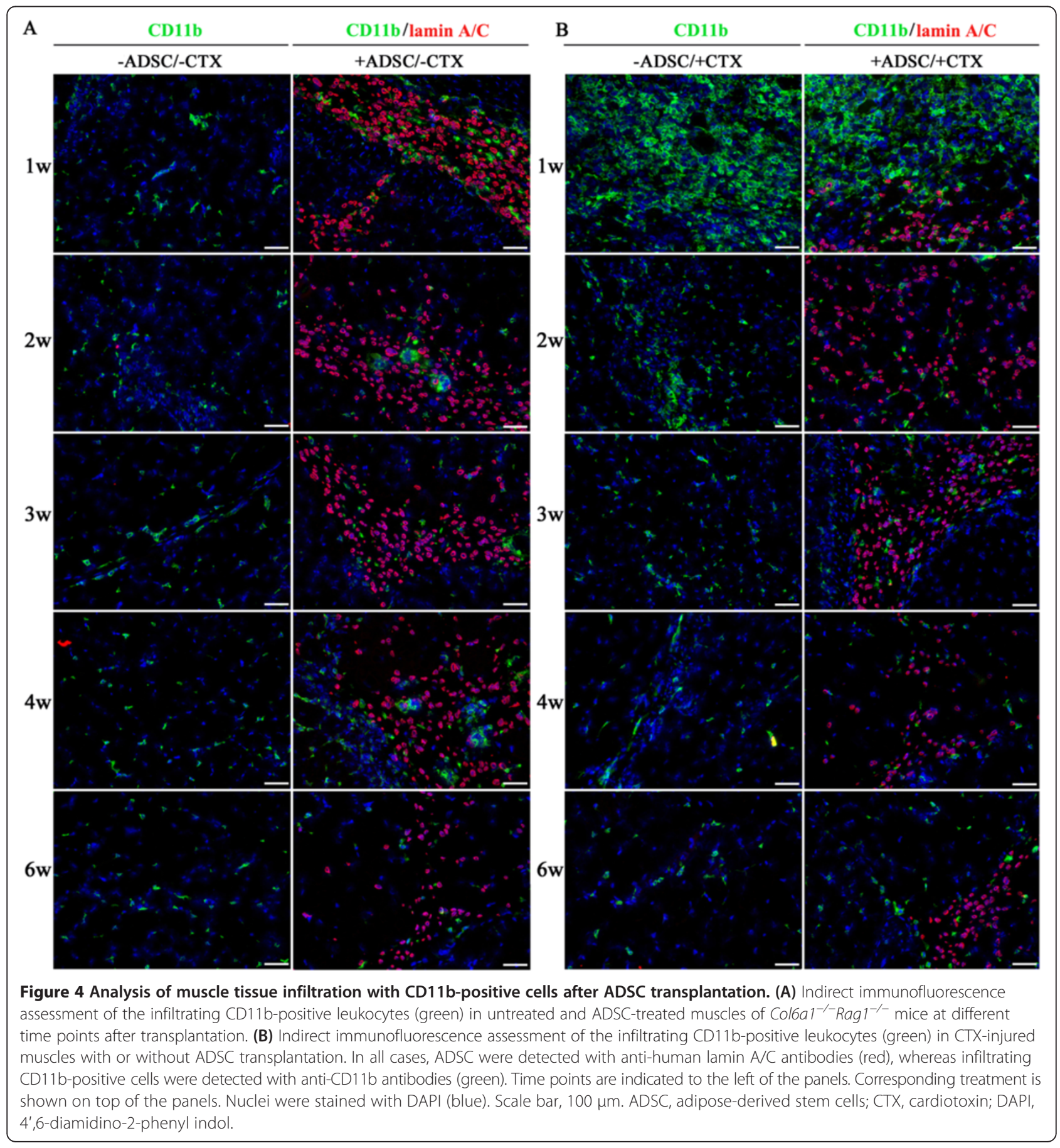


Col6a1 $1^{-1-} \mathrm{Rag1}^{-/-}$mice and thereby exacerbate the muscle abnormality. In order to enhance the regenerative response from donor stem cells, DiOC18-ADSC were injected into the left GCM two days prior to CTX injury and were traced at various time points after transplantation by systematic screening of histological sections. The right GCM was injected with CTX only as internal control. As expected, the direct injection of CTX into the GCM resulted in severe tissue injury in both control and ADSC transplanted muscle tissues. Histological analysis demonstrated global myofiber fragmentation and edema at one week after cell transplantation and five days after CTX treatment (Figure 5A). The CTX-injured muscle showed necrosis, disorganized muscle architecture and

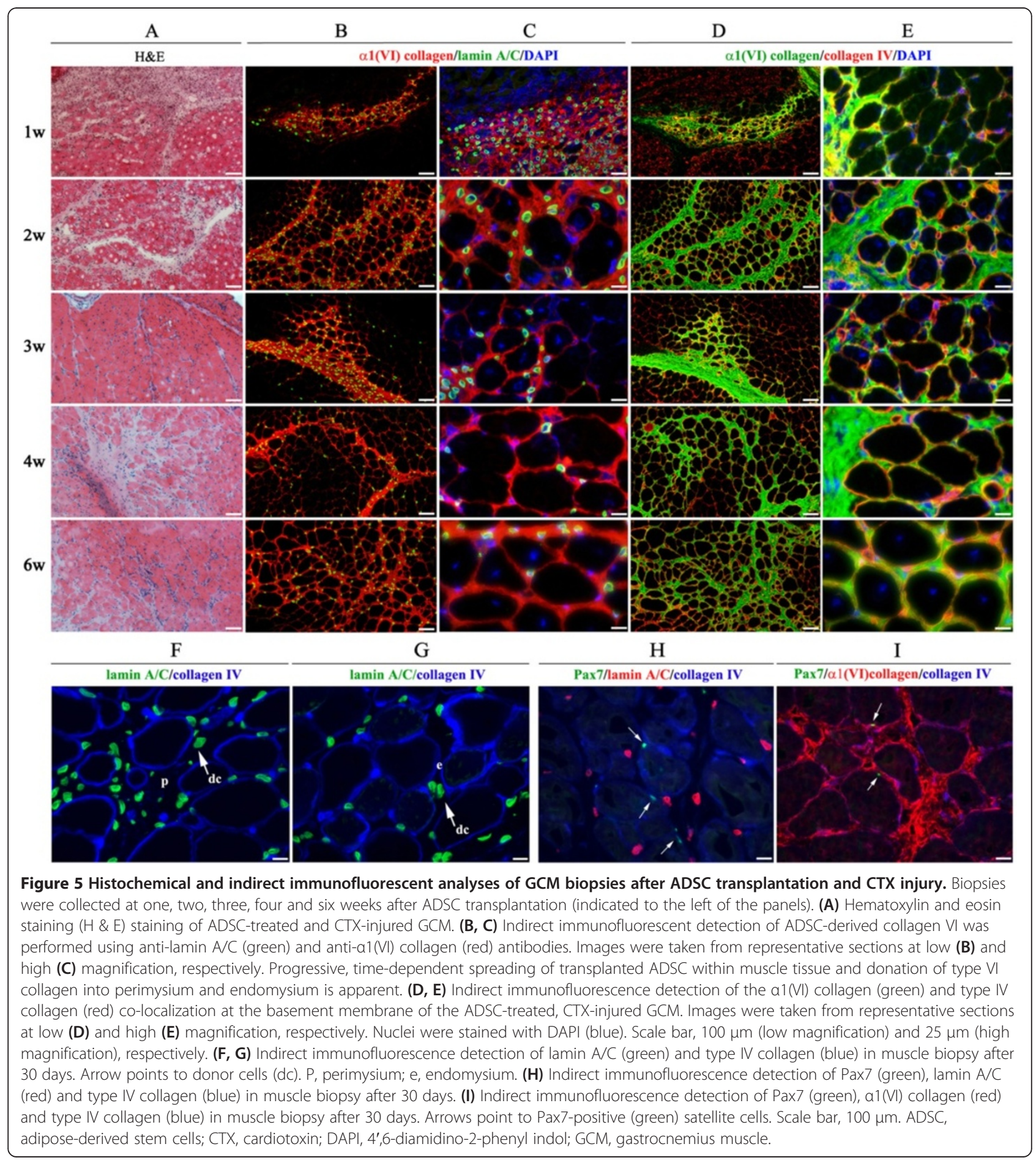


infiltration with mononucleated cells across the sectional area, mostly attributed to inflammatory cells (Figures 4B and $5 \mathrm{~A}$ ). Although the majority of transplanted cells were detected in perimysial space, small groups of the transplanted ADSC were readily found in close proximity to the injury site with already detectable collagen VI-positive myofibers. At two weeks post-ADSC injection, the CTXtreated muscles had numerous clusters of regenerating myofibers as judged by their small diameter, basophilic cytoplasm and centrally located nuclei. The level of engraftment did not change significantly and sustained at the level of $20 \%$ up to six weeks after transplantation (Figure 6A). Importantly, in CTX-treated muscles receiving ADSC transplant the number of collagen VI positive myofibers significantly increased (four-fold) in next three to six weeks (Figure 6B). Furthermore, the muscle morphology at three to six weeks post-ADSC injection/CTX injury was not different from that of the non-injured control muscles except for the presence of numerous myofibers with centrally positioned nuclei (Figures 5B-E), a known hallmark of recent muscle regeneration. Moreover, the number of CD11b infiltrating macrophages reduced dramatically, indicating the completion of the acute tissue damage phase (Figure 4B). The functionality of the ADSCproduced collagen VI was confirmed by double immunostaining with collagen $\alpha 1$ (VI) and IV antibodies, showing co-localization of both proteins at the basement membrane of individual myofibers (Figure 5D and E). It is well known that the muscle-specific stem cells, such as satellite cells, have a unique anatomical location and are positioned between the sarcolemma and the basal lamina of the muscle fibers. To see whether the transplanted ADSC can contribute to the satellite cell compartment and/or participate in formation of new myofibers, we examined the location of ADSC on the sections positively stained for donor engrafts in relation to the position of Pax7-positive satellite cells. In all examined sections of three and four week biopsies, human lamin A/C-positive cells were detected residing in the interstitial space of perimysium as well as endomysium surrounding individual muscle fibers (Figure 5F, G). Double-immunostaining with antibodies for human lamin $\mathrm{A} / \mathrm{C}$ and mouse Pax7 did not show any overlapping signals (Figure $5 \mathrm{H}$ ), suggesting that donor cells had not entered the satellite cell niche or acquired muscle stem cell phenotype (Figure $5 \mathrm{H}$ ). Moreover, regenerating and newly-formed collagen VI-positive myofibers did not show any lamin A/C-positive nuclei (Figure 5C), suggesting that the donor ADSC had not fused with mouse muscle fibers and had not directly participated in the formation of newly regenerating fibers. However, it was evident that ADSC-produced collagen VI was present at the basement membrane surrounding Pax7 cells (Figure 5I), suggesting that restored collagen VI expression may provide better mechanical properties to satellite cell niche and affect satellite cell activity. Overall, our data strongly suggest that collagen VI-donating ADSC were able to migrate intramuscularly in response to pro-migratory factors released in the course of CTX-
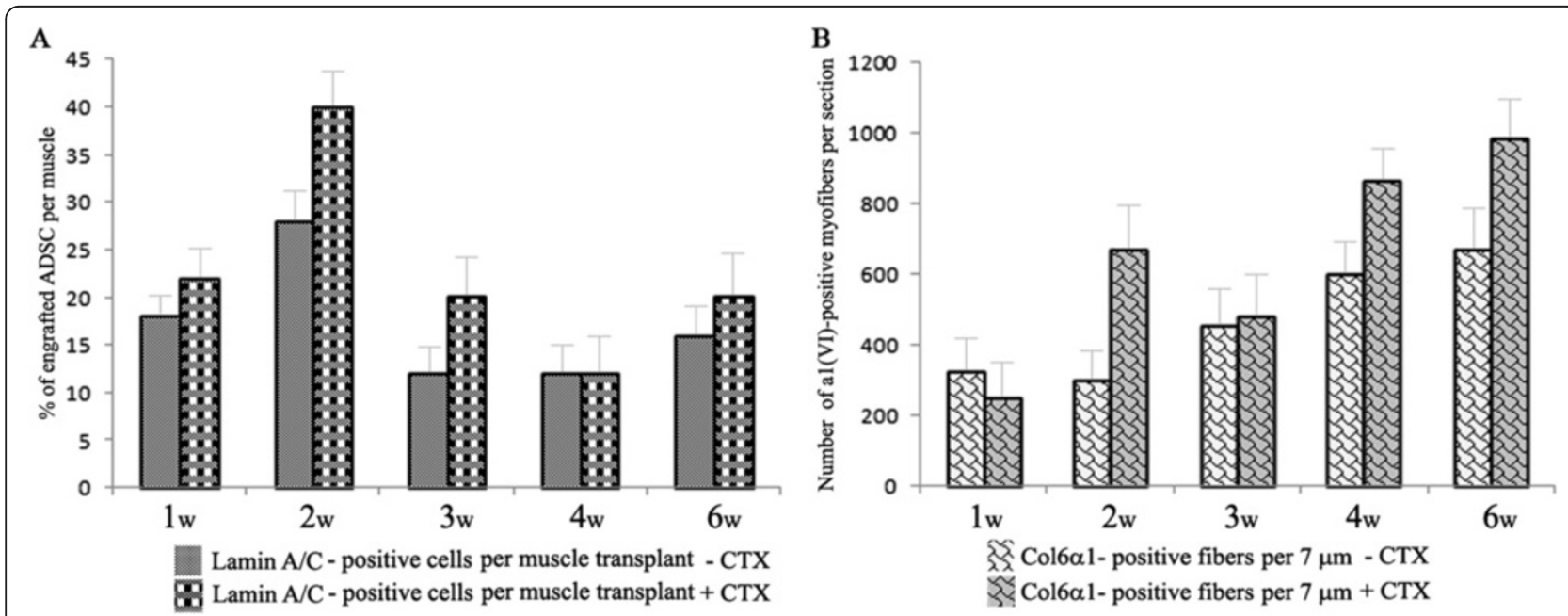

Figure 6 Comparative morphometric analysis of ADSC engraftment and type VI collagen distribution in homeostatic and CTX-treated GCM, respectively. Analysis was performed at one, two, three, four and six weeks post-transplantation and CTX injury. (A) Engraftment of ADSC into the GCM with or without CTX treatment. The vertical axis shows the percentage (\%) of engrafted ADSC per injected muscle. The horizontal axis shows the time point after transplantation in weeks (w). (B) Morphometric analysis of a1(VI)-positive myofibers in the transplanted GCM with or without CTX treatment. The vertical axis shows the number of a1(VI)-positive myofibers per section. The horizontal axis shows the time point after transplantation in weeks (w). In all cases, ADSC were detected with anti-lamin A/C antibodies. The percentage of engrafted cells and the number of a1(VI)-positive myofibers were determined on at least fifty $7 \mu \mathrm{m}$ cryosections, respectively, covering approximately $125 \mathrm{~mm}^{3}$ of muscle tissue. In all studies, at least five animals were analyzed per time point. Data is presented as average \pm SD. ADSC, adipose-derived stem cells; CTX, cardiotoxin; GCM, gastrocnemius muscle; SD, standard deviation. 
induced injury and regeneration, and they continued to produce collagen VI protein in muscle of Colba1 $1^{-/-}$ $\operatorname{Rag1}^{-1-}$ mice.

\section{Discussion}

This study exploits the novel application of stem cell therapy specific for COL6 CMD. We tested the hypothesis that collagen VI secreted by ADSC in the ECM can ameliorate the genetic impairment of skeletal muscles in the COL6 CMD mouse model. We developed a novel procedure for isolation of ADSC from neonatal human skin discarded after newborn circumcision and demonstrated that established cultures represent a morphologically homogeneous population of cells with phenotypic and functional features of mesenchymal progenitors. Also, we conducted a comprehensive gene expression profile of ADSC with special emphasis on ECM and adhesion molecules. Furthermore, we showed for the first time that locally transplanted ADSC are capable of donating collagen VI protein into muscle of Col6 $\mathrm{I}^{-/-}$mice under physiological and CTX-injury/regeneration conditions.

Adult stem cells represent a diverse group of stem cells, which are characterized by their ability to self-renew and their ability to differentiate along multiple lineage pathways. These unique features make these cells an attractive therapeutic option for transplantation and regeneration of damaged tissues. The most common type of adult stem cells is multipotent MSC, which can be isolated from several sources, including bone marrow, adipose tissue, dental pulp, placenta, umbilical cord and fallopian tube [23]. MSC isolated originally from bone marrow are defined as fibroblast-like cells with extensive proliferation capacity in culture and the ability to differentiate in vitro into various connective tissue cell types [28,29]. Recent advances in stem cell biology have shown that adult stem cells isolated from adipose tissue exhibit a number of properties suggesting the feasibility of their use as therapeutic cells [22]. The most important features of adipose tissue are its abundance in the body, relatively simple isolation procedures, expandability to relatively large quantities under minimal conditions and the ability to engraft after local or systemic reintroduction [22,23].

Here, we developed a novel procedure for the isolation of ADSC from neonatal human skin discarded after newborn circumcision and demonstrated that established cultures represent population of cells with features of mesenchymal progenitors. The developed isolation protocol proved to be a reliable approach to prepare a homogeneous fraction of human ADSC. Our antigenic cell surface profile is consistent with a previously published immunophenotypic analysis available for adult stem cells [23]. A hallmark characteristic of stem cells is their self-renewal potential and ability to differentiate into several cell lineages in vitro with the appropriate inductive media. The established ADSC cultures were able to differentiate toward adipogenic, osteogenic and chondrogenic lineages in vitro in the presence of lineage specific differentiation factors. Successful differentiation was confirmed by morphological changes demonstrated using lineage specific staining and gene expression analysis of genetic markers for the cell type of interest. Overall, these results are consistent with previously published works.

Multiple gene expression profiling studies have shown that adult stem cells, in particular MSC, can produce a vast array of proteins, including growth factors, cytokines, ECM and adhesion molecules [30]. However, no data are available regarding the expression of ECM and related genes by human neonatal ADSC. Our comprehensive gene expression analysis has shown that neonatal ADSC express a plethora of various ECM molecules, including many collagens and laminins, as well as adhesion molecules and other ECM-related genes. Of special interest to this study is collagen VI, ultimate cause of COL6 CMD. We show that ADSC produce a significant level of all three collagen VI mRNAs, in particular COL6A1. The use of ADSC for the treatment of COL6 CMD thus seems to be a logical choice since the cells are able to supply continuously the missing normal collagen VI protein.

Cell-based therapy has been explored for different types of muscular dystrophies, in particular, Duchenne muscular dystrophy [19,31]. The majority of these studies evaluated muscle derived progenitor or stem cells, such as myoblasts, side population cells, myogenic endothelial cells and mesoangioblasts. Several studies have tested stem cells derived from non-muscle tissues [32-34]. The transplanted cells were found to have limited ability to regenerate muscle fibers but were capable of reducing inflammation through trophic effects produced by transplanted cells $[33,35]$. Thus, even though a range of therapeutic approaches have been investigated for traditional muscular dystrophies, there is a need to develop treatment strategies that specifically target muscle ECM alterations. In the skeletal muscle, collagen VI is synthesized by muscle fibroblasts rather than muscle cells [8]. This is in stark contrast to most other muscular dystrophies in which the gene mutations usually involve intracellular or cell surface proteins produced by muscle cells. Therefore, the ability of stem cells to differentiate into muscle cells is not crucial for the therapeutic intervention of COL6 CMD. Moreover, the multi-lineage differentiation capacity of these cells is ideally suited for therapeutic intervention of COL6 CMD in which different connective tissue cell types need to be replenished. Also, apart from the cell regeneration capacity, an emerging therapeutic application of the stem cell therapy takes advantage of their ability to secrete cytokines and growth factors that are anti-apoptotic, pro-angiogenic, anti-inflammatory and anti-fibrotic [36]. Increased muscle cell apoptosis and 
interstitial fibrosis are typical pathological features of CMDs; therefore, stem cell transplantation likely will be beneficial even without cell differentiation and regeneration.

In this study, the therapeutic potential of neonatal ADSC was examined after local intramuscular injection into the GCM of Col6a1 $1^{-/-} \mathrm{Rag1}^{-/-}$mice, allowing human cell transplantation without immune rejection. Our study has shown for the first time that ADSC contributed robustly to the collagen VI-deficient GCM by providing efficient engraftment, wide-distribution of therapeutic cells in muscle tissue, continuous production of collagen VI protein by engrafted cells throughout the observation period and proper assembly of collagen VI microfibrils in the interstitial connective tissue of muscle, thus achieving restoration of the affected muscle basement membrane. One of the striking observations is the location of donor cells within the muscle tissue at initial stages of transplantation. During the first two weeks, the vast majority of ADSC was preferentially detected in perimysial space with very few cells in endomysium. Such unique locale could be explained by the fact that the muscle ECM, which is rich in connective tissue and adhesion proteins, may provide a proper environment for firm anchorage/attachment of ADSC. Once cells are acclimated to the perimysial environment, they start to migrate along endomysium, possibly in response to pro-migratory factors secreted by resident interstitial fibroblasts and muscle cells. Importantly, the number of $\alpha 1(\mathrm{VI})$ collagen-positive myofibers was markedly increased (two-fold) at week six as compared to the first week of transplantation, suggesting the possibility of long-term commitment of ADSC in the muscle environment.

The capacity of neonatal ADSC to participate in the regeneration of skeletal muscle was further evaluated using the CTX-induced myonecrosis model with actively ongoing regeneration and remodeling of muscle tissue. Several important observations were made during these studies. It is believed that the depletion of the satellite cell pool with consequent irreversible muscle degeneration is responsible for terminal muscle failure in DMD, COL6 CMD and, possibly, other muscular dystrophies $[37,38]$. Restoration of the regeneration potential of muscle tissue by transplanted stem cells may provide long-term efficacy for muscle homeostasis. This notion is strongly supported by a recent observation that transplantation of wild-type fibroblasts into Col6al null mice was able to ameliorate regeneration and satellite cell homeostasis by restoring muscle mechanical properties and satellite cell activity [38]. However, these effects may be somehow limited by the fact that the grafted cells are differentiated fibroblasts. Our data clearly demonstrate that ADSC are able to colonize in muscle, sustaining their long-term maintenance and the continuous replenishment of collagen VI.
However, our data demonstrated that ADSC do not directly participate in the repair of CTX-damaged muscle fibers. Immunofluorescent analysis did not show any ADSC entering the satellite niche, as judged by the position of lamin $\mathrm{A} / \mathrm{C}$-positive cells in newly regenerated myofibers. In addition, double-immunostaining of CTXtreated biopsies with lamin $\mathrm{A} / \mathrm{C}$ (donor human cells) and Pax7 (a marker for both quiescent and activated satellite cells) antibodies did not show any overlapping signals. Taken together, these data suggest that ADSC may not possess cell-autonomous properties supporting myogenic differentiation in vivo. Also, it may suggest that CTX treatment alone does not induce or enhance production of supporting factors to provide a more conducive environment for ADSC to go through myogenic commitment. Nevertheless, CTX-treated muscles receiving the ADSC transplant showed a significant increase (four-fold) in the number of collagen VI-positive myofibers at the sixth week compared to the first week of transplantation and a two-fold increase compared to transplanted muscle without CTX-injury at the sixth week. It is important to note that ADSC engraftment was not dependent on ablative injury, as cells also contributed at high efficiency (approximately 20\%) after transplantation into the GCM and sustained at this level throughout the study. However, it is interesting to note that after CTX-injury collagen VIdonating ADSC were able to migrate intramuscularly from their initial perimysial locale shortly after transplantation to the CTX-injected site, and eventually repopulated a significant area of the damaged tissue and adjacent myofibers. This directional migration from perimysium to endomysium could possibly be induced in response to pro-migratory factors released in the course of CTXinjury and regeneration, elicited by various mechanisms. As one explanation, it is likely that pro-inflammatory cytokines, chemokines and growth factors that typically result in homing of immune cells to a damaged site are released from muscle resident cells, stimulating directional migration of ADSC within muscle tissue. In fact, a prominent feature of CTX-injured muscle is a striking inflammatory infiltrate of immune cells, such as macrophages and neutrophils. Also, it is well known that CCR2 and CXCR2 are major regulators of induced macrophage and neutrophils trafficking in vivo $[39,40]$. In addition, the CXCR4-CXCL12 chemotactic axis was shown to play a significant role in regulating migration of both proliferating and terminally differentiated muscle cells [41]. Based on our assessment of chemokine receptors on ADSC, it is plausible that ADSC expressing those receptors can be recruited to the CTX-damaged site by the chemotactic mechanisms of inflammatory and satellite cells, respectively. Also, it is possible that abnormal signaling due to the deficient ECM leads to secretion of various chemokines, which may activate corresponding receptors on 
ADSC and facilitate migration toward the highest concentration of chemokine(s). Together, these observations suggest that mobilization of ADSC in CTX-damaged muscle may highly depend on the local inflammatory state rather than other factors. The ability of ADSC to donate the protein of interest to the injured muscle strongly supports the possibility of stem cell therapy for COL6 CMD, which exhibits substantially more severe myopathology than the mouse model.

\section{Conclusions}

In summary, our data provided proof-of-concept that ADSC can serve as a 'cell factory' to produce ECM molecules, such as collagen VI, which can potentially correct the protein deficiency of COL6 CMD patients. Our data also suggest that a systemic administration of stem cells can be beneficial to counteract the disease phenotype in the different muscles. A significant obstacle in designing stem cell-based therapy for COL6 CMD and other muscular dystrophies is the necessity to reach the entire body musculature, a problem that cannot be easily overcome unless systemic transplantation protocols are proved to be effective. Further investigations are required to address these important issues. Our results provide evidence supporting the suitability of ADSC as a prospective therapy for COL6 CMD. If successful, the therapeutic capabilities of stem cells could be extended to other ECM-related muscular dystrophies that are in need of more effective treatment options.

\section{Additional files}

Additional file 1: Table S1. Microsoft Word. A table presenting the sequences of primers used in the study.

Additional file 2: Table S2. Microsoft Word. A table presenting the differential expression analysis in primary human neonatal ADSC.

\section{Abbreviations \\ ADSC: adipose-derived stem cells; ALP: alkaline phosphatase; BSA: bovine serum albumin; CMD: congenital muscular dystrophy; COL6 CMD: collagen VI congenital muscular dystrophy; CTX: cardiotoxin; DAPI: 4',6-diamidino-2- phenyl indol; (D)MEM/F12: (Dulbecco's) modified Eagle's medium; ECM: extracellular matrix; EDTA: ethylenediaminetetraacetic acid; FACS: fluorescence-activated cell sorting; FBS: fetal bovine serum; FITC: fluorescein isothiocyanate; GCM: gastrocnemius muscle; H \& E: hematoxylin and eosin; MSC: mesenchymal stem cells; PBS: phosphate- buffered saline; RT-PCR: reverse-transcriptase polymerase chain reaction; UCMD: Ullrich congenital muscular dystrophy.}

\section{Competing interests}

The authors declare that they have no competing interests.

\section{Authors' contributions}

VA participated in the design of experiments, carried out the molecular analysis of cells, cell transplantation into animals, interpretation and analysis of in vitro and in vivo data, and helped to draft the manuscript. MA and $A D$ participated in all experiments involving animals, including colony maintenance, genotyping, collection of biopsies, histological and immunofluorescence analyses. PB conceived of the study, participated in its design and helped to draft the manuscript. OI and MLC have been involved in all aspects of the study, including experimental design, characterization of cells, gene expression study, transplantation studies, analysis and interpretation of data and manuscript writing. All authors read and approved the final manuscript.

\section{Acknowledgements}

This work was supported by Cure CMD Foundation to Ol.

\section{Author details}

'Department of Dermatology and Cutaneous Biology, Jefferson Medical College, Thomas Jefferson University, BLSB, Rm. 430, 233 South 10th Street, Philadelphia, PA 19107, USA. ${ }^{2}$ Departments of Biomedical Sciences, University of Padova, Padova 35131, Italy.

Received: 16 September 2013 Revised: 12 December 2013 Accepted: 20 December 2013 Published: 12 Feb 2014

\section{References}

1. Bonnemann CG: The collagen VI-related myopathies: muscle meets its matrix. Nat Rev Neurol 2011, 7:379-390.

2. Betrini $E, D^{\prime}$ Amico A, Gualandi F, Petrini $S$ : Congenital muscular dystrophies: a brief review. Semin Pediatr Neurol 2011, 18:277-288.

3. Norwood FL, Harling C, Chinnery PF, Eagle M, Bushby K, Straub V: Prevalence of genetic muscle disease in Northern England: in-depth analysis of a muscle clinic population. Brain 2009, 132:3175-3186.

4. Okada M, Kawahara G, Noguchi S, Sugie K, Murayama K, Nonaka I, Hayashi YK, Nishino I: Primary collagen VI deficiency is the second most common congenital muscular dystrophy in Japan. Neurology 2007, 69:1035-1042.

5. Peat RA, Smith JM, Compton AG, Baker NL, Pace RA, Burkin DJ, Kaufman SJ, Lamande SR, North KN: Diagnosis and etiology of congenital muscular dystrophy. Neurology 2008, 71:312-321.

6. Lampe AK, Bushby KM: Collagen VI related muscle disorders. J Med Genet 2005, 42:673-685

7. Braghetta P, Ferrari A, Fabbro C, Bizzotto D, Volpin D, Bonaldo P, Bressan GM: An enhancer required for transcription of the Col6a1 gene in muscle connective tissue is induced by signals released from muscle cells. Exp Cell Res 2008, 314:3508-3518.

8. Zou Y, Zhang RZ, Sabatelli P, Chu ML, Bonnemann CG: Muscle interstitial fibroblasts are the main source of collagen VI synthesis in skeletal muscle: implications for congenital muscular dystrophy types Ullrich and Bethlem. J Neuropathol Exp Neurol 2008, 67:144-154.

9. Chu ML, Pan TC, Conway D, Saitta B, Strokes D, Kuo HJ, Glanville R, Timple R, Mann K, Deutzmann R: The structure of type VI collagen. Ann N Y Acad Sci 1990, 580:55-63.

10. Camacho Vanegas O, Bertini E, Zhang RZ, Petrini S, Minosse C, Sabatelli P, Giusti B, Chu ML, Pepe G: Ullrich scleroatonic muscular dystrophy is caused by recessive mutations in collagen type VI. Proc Natl Acad Sci U S A 2001, 98:7516-7521.

11. Higuchi I, Shiraishi T, Hashiguchi T, Suehara M, Niiyama T, Nakagawa M, Arimura K, Maruyama I, Osame M: Frameshift mutation in the collagen VI gene causes Ullrich's disease. Ann Neurol 2001, 50:261-265.

12. Demir E, Sabatelli P, Allamand V, Ferreiro A, Moghadaszadeh B, Makrelouf M, Topaloglu H, Echenne B, Merlini L, Guicheney P: Mutations in COL6A3 cause severe and mild phenotypes of Ullrich congenital muscular dystrophy. Am J Hum Genet 2002, 70:1446-1458.

13. Bonaldo P, Braghetta P, Zanetti M, Piccolo S, Volpin D, Bressan GM: Collagen VI deficiency induces early onset myopathy in the mouse: an animal model for Bethlem myopathy. Hum Mol Genet 1998, 7:2135-2140.

14. Angelin A, Tiepolo T, Sabatelli P, Grumati P, Bergamin N, Golfieri C, Mattioli E, Gualandi F, Ferlini A, Merlini L, Maraldi L, Bonaldo P, Bernardi P: Mitochondrial dysfunction in the pathogenesis of Ullrich congenital muscular dystrophy and prospective therapy with cyclosporins. Proc Natl Acad Sci U S A 2007, 104:991-996.

15. Irwin WA, Bergamin N, Sabatelli P, Reggiani C, Megighian A, Merlini L, Braghetta P, Columbaro M, Volpin D, Bressan GM, Bernardi P, Bonaldo P: Mitochondrial dysfunction and apoptosis in myopathic mice with collagen VI deficiency. Nat Genet 2003, 35:367-371.

16. Grumati P, Coletto L, Sabatelli P, Cescon M, Angelin A, Bertaggia E, Blaauw B, Urciuolo A, Tiepolo T, Merlini L, Maraldi NM, Bernardi P, Sandri M, Bonaldo $P$ : Autophagy is defective in collagen VI muscular dystrophies, and its reactivation rescues myofiber degeneration. Nat Med 2010, 16:1313-1320. 
17. Merlini L, Angelin A, Tiepolo T, Braghetta P, Sabatelli P, Zamparelli A, Ferlini A, Maraldi NM, Bonaldo P, Bernardi P: Cyclosporin A corrects mitochondrial dysfunction and muscle apoptosis in patients with collagen VI myopathies. Proc Natl Acad Sci U S A 2008, 105:5225-5229.

18. Merlini L, Sabatelli P, Armaroli A, Gnudi S, Angelin A, Grumati P, Michelini ME, Franchella A, Gualandi F, Bertini E, Maraldi NM, Ferlini A, Bonaldo P, Bernardi P: Cyclosporine A in Ullrich congenital muscular dystrophy: long-term results. Oxid Med Cell Longev 2011, 2011:139194.

19. Meregalli M, Farini A, Parolini D, Maciotta S, Torrente Y: Stem cell therapies to treat muscular dystrophy: progress to date. BioDrugs 2010, 24:237-247.

20. Kassem M, Abdallah BM: Human bone-marrow-derived mesenchymal stem cells: biological characteristics and potential role in therapy of degenerative diseases. Cell Tissue Res 2008, 331:157-163.

21. Augello A, De Bari C: The regulation of differentiation in mesenchymal stem cells. Hum Gene Ther 2010, 21:1226-1238.

22. Fraser JK, Wulur I, Alsonso Z, Hedrick M: Fat tissue: an underappreciated source of stem cells for biotechnology. Trends in Biotech 2006, 24:150-154.

23. Kern S, Eichler H, Stoeve J, Kluter H, Bieback K: Comparative analysis of mesenchymal stem cells from bone marrow, umbilical cord, or adipose tissue. Stem Cells 2006, 24:1294-1301.

24. Tse WT: Suppression of allogeneic T-cell prolferation by humna marrow stromal cells: implications in transplantation. Transplantation 2003 75:389-397.

25. Tillet E, Wiedemann H, Golbik R, Pan TC, Zhang RZ, Mann K, Chu ML, Timpl $R$ : Recombinant expression and structural and binding properties of alpha $1(\mathrm{VI})$ and alpha $2(\mathrm{VI})$ chains of human collagen type $\mathrm{VI}$. Eur J Biochem 1994, 221:177-185.

26. Zhang RZ, Zou Y, Pan TC, Markova D, Fertala A, Hu Y, Squarzoni S, Reed UC, Marie SK, Bonnemann CG, Chu ML: Recessive COL6A2 C-globular missense mutations in Ullrich congenital muscular dystrophy: role of the C2a splice variant. J Biol Chem 2010, 285:10005-10015.

27. Specks U, Mayer U, Nischt R, Spissinger T, Mann K, Timpl R, Engel J, Chu ML: Structure of recombinant $\mathrm{N}$-terminal globule of type $\mathrm{VI}$ collagen alpha 3 chain and its binding to heparin and hyaluronan. EMBO J 1992, 11:4281-4290.

28. Dominici M, Le Blanc K, Mueller I, Slaper-Cortenbach I, Marini F, Krause D, Deans R, Keating A, Prockop D, Horwitz E: Minimal criteria for defining multipotent mesenchymal stromal cells. The International Society for Cellular Therapy position statement. Cytotherapy 2006, 8:315-317.

29. Kolf CM, Cho E, Tuan RS: Mesenchymal stromal cells. Biology of adult mesenchymal stem cells: regulation of niche, self-renewal and differentiation. Arthritis Res Ther 2007, 9:204

30. Alexeev V, Uitto J, Igoucheva O: Gene expression signatures of mouse bone marrow-derived mesenchymal stem cells in cutaneous environment and therapeutic implications for blistering skin disorder. Cytotherapy 2011, 13:30-45

31. Farini A, Razini P, Erratico S, Torrente Y, Meregalli M: Cell based therapy for Duchenne muscular dystrophy. J Cell Physiol 2009, 221:526-534.

32. De Bari C, Dell'Accio F, Vandenabeele F, Vermeesch JR, Raymackers JM, Luyten FP: Skeletal muscle repair by adult human mesenchymal stem cells from synovial membrane. J Cell Biol 2003, 160:909-918.

33. Meng J, Adkin CF, Arechavala-Gomeza V, Boldrin L, Muntoni F, Morgan JE: The contribution of human synovial stem cells to skeletal muscle regeneration. Neuromuscul Disord 2010, 20:6-15.

34. Vieira NM, Bueno CR Jr, Brandalise V, Moraes LV, Zucconi E, Secco M, Suzuki MF, Camargo MM, Bartolini P, Brum PC, Vainzof M, Zatz M: SJL dystrophic mice express a significant amount of human muscle proteins following systemic delivery of human adipose-derived stromal cells without immunosuppression. Stem Cells 2008, 26:2391-2398.

35. da Justa Pinheiro CH, de Queiroz JC, Guimaraes-Ferreira L, Vitzel KF, Nachbar RT, de Sousa LG, de Souza-Jr AL, Nunes MT, Curi R: Local injections of adipose-derived mesenchymal stem cells modulate inflammation and increase angiogenesis ameliorating the dystrophic phenotype in dystrophin-deficient skeletal muscle. Stem Cell Rev 2012, 8:363-374.

36. Ichim TE, Alexandrescu DT, Solano F, Lara F, Campion RN, Paris E, Woods EJ, Murphy MP, Dasanu CA, Patel AN, Marleau AM, Leal A, Riordan NH: Mesenchymal stem cells as anti-inflammatories: implications for treatment of Duchenne muscular dystrophy. Cell Immunol 2010, 260:75-82.
37. Cossu G, Mavilio F: Myogenic stem cells for the therapy of primary myopathies: wishful thinking or therapeutic perspective? J Clin Invest 2000, 105:1669-1674.

38. Urciuolo A, Quarta M, Morbidoni V, Gattazzo F, Molon S, Grumati P, Montemurro F, Tedesco FS, Blaauw B, Cossu G, Vozzi G, Rando TA, Bonaldo P: Collagen VI regulates satellite cell self-renewal and muscle regeneration. Nat Commun 1964, 2013:4.

39. Kuziel WA, Morgan SJ, Dawson TC, Griffin S, Smithies O, Ley K, Maeda N: Severe reduction in leukocyte adhesion and monocyte extravasation in mice deficient in CC chemokine receptor 2. Proc Natl Acad Sci USA 1997, 94:12053-12058.

40. Zhang XW, Wang Y, Liu Q, Thorlacius H: Redundant function of macrophage inflammatory protein-2 and $\mathrm{KC}$ in tumor necrosis factor-alpha-induced extravasation of neutrophils in vivo. Eur J Pharmacol 2001, 427:277-283.

41. Griffin CA, Apponi LH, Long KK, Pavlath GK: Chemokine expression and control of muscle cell migration during myogenesis. J Cell Sci 2010, 123:3052-3060.

\section{$10.1186 /$ scrt411}

Cite this article as: Alexeev et al:: Human adipose-derived stem cell transplantation as a potential therapy for collagen VI-related congenital muscular dystrophy. Stem Cell Research \& Therapy 2014, 5:21

\section{Submit your next manuscript to BioMed Central and take full advantage of:}

- Convenient online submission

- Thorough peer review

- No space constraints or color figure charges

- Immediate publication on acceptance

- Inclusion in PubMed, CAS, Scopus and Google Scholar

- Research which is freely available for redistribution

Submit your manuscript at www.biomedcentral.com/submit
C Biomed Central 